\title{
SYNTACTIC AND PRAGMATIC FEATURES: A CASE STUDY
}

Roberta D'Alessandro

University of Cambridge

Abstract: In the generative literature, it has always been assumed that syntactic agreement takes place by means of syntactic operations that target the so-called phi-features. Lexical items are not atomic, but rather made up of phonetic material plus syntactic features, which encode grammatical information regarding, for example, number, gender, person, and case. According to Chomsky's Derivation by Phase, syntactic agreement happens between two lexical items when two operations take place: Merge and Agree. If both these operations occur, syntactic agreement is established. In this paper, I shall move some objections against the traditional idea of phi-features and agreement. These objections derive directly from data observation. I shall show that some agreement and interpretational patterns of Italian impersonal si and European Portuguese a gente constructions are unexplainable within the current generative theory. I shall therefore argue for the existence of an additional set of features encoding pragmatic/deictic information. This feature set, which I call the sigma-set (see D'Alessandro, 2004), is responsible for the so-called semantic agreement phenomena that have often been considered as solely acting in the pragmatic component of the grammar (Wechsler and Zlatić, 2001). I propose instead that pragmatic information is encoded syntactically, in the sigma-set, which appears at least in personal pronouns.

Keywords: syntactic features; pragmatic features; agreement

\section{Introduction}

In this paper, I wish to show that some agreement phenomena are not explainable by means of the traditional theory of agreement. The present paper is structured as follows: In the remainder of this section, a short theoretical background is provided. In section 2 , some problematic data are presented, and some generally shared assumptions are shown to be defective in many ways. Section 3 contains the proposal that an additional feature set exists, the sigmaset, which is necessary in order to explain the phenomena at issue. In 4 , some possible applications of the sigma-set are sketched. Section 5 contains my conclusions. 


\subsection{Theoretical background: Match and Agree}

According to the model outlined in Chomsky (1999), syntactic expressions must be interpretable at the interface between the syntactic system and other systems, such as the phonological or the logical system. In other words, for a syntactic expression to be interpretable, it must reach the interface level with other systems not carrying any uninterpretable feature.

Chomsky (1999) proposes a mechanism of elimination of uninterpretable features that can be summarized as follows: phifeatures, i.e. syntactic features like gender, number, person, may be unvalued, and thus uninterpretable at the interface level. These features need to be valued and possibly eliminated for the interpretation of a syntactic structure to be possible at the interface level. Phi-features are usually interpretable (i.e. valued) on lexical heads and uninterpretable on functional heads. As an example, the Italian lexical item casa ('house') has interpretable number (singular) and gender (feminine) features; but has unvalued Case.

For the valuation of features to take place, Match between phifeatures on lexical items must operate. The Match operation takes place between a Probe and a Goal as soon as possible after they enter the derivation. If Match takes place, Agree can subsequently take place. Under Agree, unvalued (i.e. uninterpretable) features can be valued and deleted from narrow syntax. According to Chomsky (1999), the domain of a Probe is its c-command domain. A specifierhead configuration is no longer necessary for agreement to take place, and agreement can take place long-distance. Locality constraints reduce to shortest c-command.

In this paper, I show that the notion of phi-features as used by Chomsky (1999) and as universally accepted in the generative framework is not sufficient to account for some agreement facts which are found in Italian and European Portuguese. I therefore postulate the existence of an additional set of features, the sigma-set, that syntactically encodes pragmatic information about the actual participants in the speech event. The mechanism of valuation of sigma features is the same as Agree. Following Uriagereka's suggestion and a long standing tradition, I call this operation Concord. Concord is a syntactic operation responsible for the valuation of the pragmatic 
sigma-features as well as for adjectival and participial agreement, that usually take place more locally.

In what follows, I first present some data that are not analyzable by means of the current featural theory, and then offer my proposal.

\section{A look at some problematic data}

In the recent years, much attention has been dedicated to the bundles of features that characterize personal pronouns. In a recent paper, Harley and Ritter (2002) showed that a system based only on person/gender/number feature is insufficient to describe the feature configuration of morphologically complex pronouns. Harley and Ritter propose a feature geometry accounting for the degree of feature markedness, as in (1):

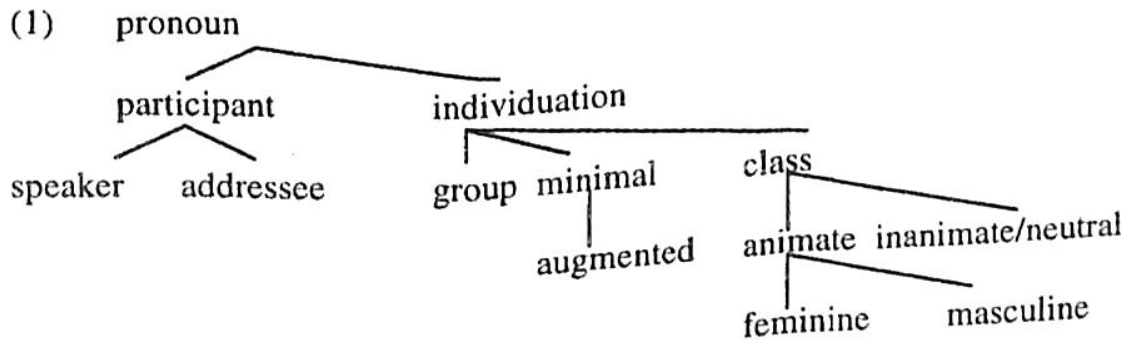

According to Harley and Ritter, pronouns have at least two big feature subgroups: participant (which includes speaker and addressee) and individuation (which includes number and gender features). The speaker and addressee nodes obviously correspond to 1 st and 2 nd person; the 3rd person is, according to Harley and Ritter, unmarked.

Harley and Ritter's geometry is revealing in several respects: It underlines the necessity of postulating a complex internal structure for pronouns, and it identifies several classes that are usually not taken into consideration when one talks about phi-features simply as gender/number/person.

Harley and Ritter's geometry, however, does not address personal pronouns. Impersonal pronouns constitute a great challenge for any theory which states that pronouns are fixed bundles of features, as their interpretation largely varies according to the context in which they appear. 
As an example, let us consider the contrast between (2) and (3):

Lui

$$
\text { è simpatico }
$$

he-3rd pers sg masc is-3rd pers sg nice-sg masc

'He is nice'

(3)

$\mathrm{Se}$

vuoi essere simpatico, devi

if pro-2nd sg want-2nd sg to-be nice-masc sg pro-2nd sg must-2nd sg essere anche ricco

to-be also rich

'If you wish to be nice, you need to be also rich'

'If one wishes to be nice, one needs to be also rich'

If the sentence in (2) is uttered out of the blue, the referent of lui is established deictically. According to the general view, the referent of lui is neither the speaker nor the addressee, and is a male person. Identifying the referent of the pronoun lui is the role of the pragmatic component, which will identify a person according to the syntactic information provided by the personal pronoun.

This line of reasoning is however feeble if one considers some semantic agreement facts that challenge this one-to-one correspondence between personal pronouns and their referents. As an example, consider sentence (3) again. Who is the referent of pro in (3)? Is it the addressee or is it a generic person?

The fact that pro in sentences like (3) may have different referents undermines the idea that there is a one-to-one correspondence between personal pronouns and their referents. Yet, one can still maintain that the pragmatic component identifies two different referents depending on the context, as one does not see any difference in agreement in either case.

In what follows, I extensively show that the one-to-one correspondence between pronouns and their referents does not always hold, and that the postulation of additional features is necessary.

\subsection{The pragmatic-syntax interface}

In the previous section, we have seen that the claim that there's a one-to-one correspondence between a pronoun and its referent may not hold. One can object, however, that the pragmatic 
component does not interact with syntax, as no signs of this interaction are visible on lexical items. In the recent literature, however, it has often been claimed that pragmatic information needs to be conveyed syntactically (Sigurðsson, 2004a, 2004b, Bianchi 2003, Speas, 2004). That the referent of a pronoun needs to be encoded in the syntactic component is evident if we consider the following gender issue. Let us consider sentence (4):
(4) $\mathrm{Tu}$
you-2nd sg
'You are nice'
sei simpatica
are-2nd sg nice-fem sg

If the gender of the referent is not encoded in the syntax, how can agreement possibly appear on the adjective?

Even more straightforward is the case of agreement in Italian impersonal si constructions, as in (5):

\section{(5) Si è}

si is-3rd sg

andati

'We went out for dinner'

fuori a cena

The sentence in (5) is interesting in two ways. First, the auxiliary verb in (5) is singular, while the past participle is plural. Second, impersonal si in (5) means 'we', i.e. it has an inclusive reading. The inclusive reading of si does not always arise, as (6) shows:
(6) Si arriva sempre tardi se si prende
si arrives-3rd sg always late if si takes-3rd sg
'One always arrives late if one takes the train'
il treno
the train

The contrast between (5) and (6) clearly indicates that the referents of si may vary. One could argue that the 'we' interpretation of $s i$ is included in its generic interpretation, as the speaker and the addressee are included among the generic referents for si. In other words, as parts of the universe, the speaker and the addressee are included among the referents of si when si holds a generic interpretation. In 2.1.1., however, it will be shown that si has an inclusive interpretation that is independent of the generic one. If $s i$ has different reference sets in (5) and (6), then there is no one-to-one correspondence between a pronoun and its referents. 
In the next section, I show that the two interpretations are independent of each other, and that the pragmatic information does need to be encoded in the syntax.

\subsubsection{The inclusive interpretation of impersonal $s i$ in Italian}

In the preceding part, I have shown that the interpretation of impersonal si varies. In other words, the pronoun $s i$ in Italian, when used impersonally, has at least two reference sets: It may mean 'we' (inclusive interpretation), and it may mean 'one' (generic interpretation). It has often been argued that the inclusive reference set of impersonal $s i$ is a subset of the generic one. In other words, since 'one', or 'people' are not better specified, they may also include the speaker. I wish to show that this is not the case.

According to Chierchia (1995), impersonal si introduces in the discourse a variable that ranges over humans. If si has a generic interpretation, the variable is bound by a universal quantifier. According to some scholars, the inclusive 'we' interpretation is just a variant of this universal-generic interpretation, in that the speaker may be included among the universe of the event participants. This is however not accurate, as that the inclusive interpretation of impersonal si exists independently of the generic interpretation.

Cinque (1995) and Kratzer (2000) propose a list of diagnostics for the inclusive interpretation. I will list here only some of them.

According to Kratzer (2000), only inclusive pronouns may license a predicative NP. The presence of a subject-related predicative NP forces an inclusive reading for pronouns. In the following sentence, (7), directly translated into Italian from Kratzer (2000, p. 4), $s i$ is clearly inclusive, as it can corefer with the predicative NP come guardiani della legge ('as guardians of the law'). This does not hold for (8), where $s i$ is not inclusive and therefore it cannot corefer with the predicative NP come guardiani della legge.

(7)

Come guardiani della legge, si è

As guardians of-the law si is- $3^{\text {rd }} \mathrm{sg}$

stati obbligati a controllare l'osservanza di tutti $i$ to control the respect of all the obliged-pp pl masc '[As guardians of the law], we were obliged to watch over the observance of all regulations' 
(8)

*Come guardiani della legge, mi

As guardians of the law to-me-dat non posso vivere qui not can- $1^{\text {st }}$ sg to-live here

'As guardians of the law, they explained to me that I could not live here'

The ungrammaticality of (8) indicates that here si is not inclusive, as it does not license a predicative NP. In (7), on the contrary, si is inclusive, as it licenses a predicative NP. The difference between (7) and (8) shows that $s i$ has a real inclusive reading in some contexts, while it does not have it in others. This in turn suggests that the inclusive interpretation is not a pragmatic specification of the generic interpretation, but that it actually exists.

Cinque (1995) offers several syntactic tests that distinguish between inclusive and generic si. According to him, inclusive si is incompatible with $3^{\text {rd }}$ person arbitrary elements, such as se stess('themselves') and propri- ('their own'), like in (9):

(9)

*Amici! Un minuto fa Friends a minute ago se stessi

themselves

'My friends! One minute ago we were left to oneself' [Cinque, 1995, p. 159, ex. 60a]

Moreover, inclusive si may occur with $1^{\text {st }}$ person plural emphatic pronouns and may resume a left dislocated or relativized $1^{\text {si }}$ person plural pronoun:
(10) $\mathrm{Si}_{\mathrm{i}} \mathrm{è}$
andati
$\mathrm{si}_{\mathrm{i}}$ is-3rd sg
'We too went out for dinner'
fuori a cena anche noi $i_{\text {, }}$ out to dinner also $\mathrm{we}_{\mathrm{i}}$

si è stati

abbandonati

a

si is been-pp pl masc abandoned-pp pl masc to

The same does not hold for the generic reading, as shown in (11):

(11)

?? $\mathrm{Si}_{\mathrm{i}}$ arriva

si arrives-3rd sg

sempre tardi anche noi $_{i}$ se $s i_{i}$ prende

il treno

'We arrive late is we take the train' 
The sentence in (11) is regionally marked. It is utterable in Tuscan Italian ${ }^{1}$, but it is much worse than (10) in Standard Italian.

We are allowed to conclude that the inclusive interpretation of impersonal si exists independently of the generic interpretation, and that therefore impersonal si constitutes a challenge for those theories that assume a one-to-one correspondence between pronouns and their referents. $S i$ has in fact more than one reference group ${ }^{2}$.

Moreover, the fact that si may bind a dislocated pronoun, as in (10), seems to suggest that its inclusiveness is encoded in the syntactic component, and consequently that inclusiveness is not a mere effect of pragmatics.

A very interesting piece of evidence for the fact that phifeatures are not enough to describe the agreement patterns of impersonal pronouns is offered by European Portuguese (EP henceforth) a gente ('people', 'we'). A gente is an impersonal pronoun, which is syntactically feminine singular, as the presence of a feminine singular determiner shows. However, the agreement patterns that a gente triggers in EP are quite surprising, as (12) shows:
(12) A gente está
cansados
a gente is- $3^{\text {rd }} \mathrm{sg}$
'People are tired'
tired-masc pl

In (12), a gente triggers masculine plural syntactic agreement on the adjective. It is quite evident that such an agreement pattern is impossible to obtain if one simply considers phi-features. If phifeatures were to determine adjectival agreement in (12), we would have a feminine singular adjective instead of the masculine plural one that we actually have.

1 For reasons of shortness, I will not consider the case of Tuscan Italian here. Tuscan Italian has a wider use of impersonal si than Standard Italian. This is probably due to the fact that the Tuscan dialect lost the 1 st person plural form of the verb, and has substituted it with the impersonal si form.

2 D'Alessandro (2004) extensively shows that event boundedness triggers the inclusive reading of si. However, for what matters in this paper, it is sufficient to observe that si may have different reference sets. For reasons of shortness, I will not address the issue of inclusiveness any further. 


\section{Sigma-features}

In the preceding section, it has been shown that phi-features are not sufficient to describe the syntactic variation of impersonal si constructions in Italian and the agreement patterns of a gente constructions in European Portuguese. I wish to propose that another feature set is present on personal pronouns: the sigma-set. This set syntactically encodes pragmatic/deictic information about the actual participants in the speech event.

Let us consider impersonal si again. Its phi-set is generally assumed to be the following (Belletti, 1982, Cinque, 1988, DobrovieSorin, 1998):

- Person: $3^{\text {rd }}$

- Number: no number

- Gender: no gender ${ }^{3}$

However, as we have seen above, the reference set of impersonal si varies. Additional information is required in order to identify $s i$ 's reference set and to permit si's binding relations. Let us then turn to consider the semantico/pragmatic information that $s i$ holds.

\subsection{Animacy}

Impersonal si always refers to humans. This property has often been referred to as 'animacy' (Anagnostopoulou, 2002, Ormazabal and Romero, 2002). I will attain to this definition, warning the reader that being human is not the same as being animate.

Impersonal si may, thus, only refer to humans. A sentence like (13) may only be interpreted as referring to people, and not to animals:

(13) Qui si abbaia tutto il giorno

Here si barks all the day

'Here people/*dogs bark all day long'

We can conclude that impersonal si bears a 'human' sigmafeature.

3 For an explanation of these features, the reader is referred to D'Alessandro (2004). 


\subsection{Number}

For the definition of the number feature of $s i$, I will follow Chierchia (1995), who extensively argues for si's semantic plurality. Si always identifies a group of people, which may or may not include the speaker.

In a sentence like (14), si may never refer to a single person, even if the adverbial specification would force a single-person reading:

(14) A casa mia si mangia bene at home my si eats well 'One eats well at my place'

We can thus conclude that $s i$ is semantically-pragmatically plural.

\subsection{Person}

The issue of the person feature of impersonal si has been the object of endless debates. According to Cinque (1988), si holds an arbitrary person feature, which provides the sentence with a generic/arbitrary subject. Cinque considers this as a syntactic person feature. However, if the division between syntactic and semantic features holds, one can easily assume that arbitrariness concerns the semantic field, not the syntactic one. In fact, it seems quite straightforward to consider si as syntactically $3^{\text {rd }}$ person, as it always triggers $3^{\text {rd }}$ person agreement on the verb, as the examination of all our examples leads to conclude.

Pragmatically, however, si is not $3^{\text {rd }}$ person. It does not mean 'someone other than the speaker or the addressee'. It means 'people', or 'one', or 'we', depending on the context in which it appears.

As shown in section 2.1., the interpretation of $s i$ varies at least between a generic and an inclusive one. In both cases, $s i$ identifies a group of people. But this group may or may not include the speaker. In other words, what varies here is the semantic person feature of $s i$.

In D'Alessandro (2004), it has been extensively argued that the interpretational variation of impersonal si is strictly related to the boundedness of the event expressed by the verb. If the event is bounded, i.e. it has a beginning and an end, according to the definition given by Iatridou et al. (2003), an inclusive interpretation arises for si. 
Hence, the sigma feature of impersonal si varies depending on the boundedness of the event. For this reason, I assume that the sigmaperson feature of impersonal $s i$ is underspecified, and it receives its specification in the course of the derivation. I will show how this happens in the next section.

\subsection{Gender feature}

$S i$ 's semantic gender feature strictly depends on the gender of the group that $s i$ refers to. It may be masculine if the group is made up of men or men and women together, or it may be feminine, if the group is only made up of women.

In order to draw a proposal for impersonal si's gender feature, I wish to introduce the notion of disjunctive feature, as proposed by Wechsler and Zlatić (2001):

(15) A disjunctive feature is a feature that includes all the possible values for that feature

A disjunctive gender feature has both values: masculine and feminine. I wish to propose that $s i$ 's gender feature is disjunctive. It is thus doubly-valued, and it embodies both values alternatively, depending on the referent of $s i$.

To sum up, si's sigma-features are the following:

- Animacy: HUMAN

- Number: PLURAL

- Person: UNDERSPECIFIED

- Gender: MASCULINE + FEMININE

\section{Sigma-features in action: Italian impersonal si and Portuguese $a$ gente}

It has often been argued (after Cinque, 1988) that the inclusive interpretation of impersonal $s i$ is obtained in contexts of specific time reference. According to D'Alessandro (2004), however, specific time reference is not sufficient for the inclusive interpretation to arise. In particular, D'Alessandro (2004) shows that the inclusive reading of $s i$ is obtained under event boundedness (Iatridou et al, 2003). 
Before presenting the derivation and the mechanism of valuation of sigma-features, I wish to introduce some assumptions I will rely on for my analysis.

First, following recent proposals by Sigurðsson (2002) and Bianchi (2003), I assume a Speech Act P that encodes the information about the actual participants in the speech act. If, for example, the argument of an event is a first person pronoun, such a pronoun will receive its pragmatic/deictic specification (i.e. actual Speaker) by being anchored to the Speech Act P. Bianchi (2003) outlines a model of feature checking for such a specification. She proposes that the lexical $1 \mathrm{st} / 2$ nd person features on a pronoun need to be checked against the Speech act head in order for the pronoun to be interpretable. I wish to follow this line, and propose that the Speech Act has valued sigma-features Speaker/Addressee.

As for the event, following recent proposals by Iatridou et al and Giorgi and Pianesi (2004), I assume that when the event is unbounded an [unbounded] feature is present on the Aspect head. This feature states that the event has no boundaries.

When the event is bounded, I assume that the [unbounded] feature is absent from the numeration. Therefore, no feature is present on the Aspect head. I propose that if the event is unbounded, the underspecified person feature enters Concord with the [unbounded] feature, resulting in a generic interpretation. If the event is bounded, the underspecified person feature cannot enter Concord with any feature of the relevant kind on the Aspect head, as no feature is present on that head. The person feature is thus valued by the Speech Act head, which carries a valued Speaker/Addressee person feature. This results in an inclusive reading.

\subsection{A derivation involving sigma-features}

In the previous section, it was argued that Italian impersonal $s i$ has different reference sets depending on the boundedness specification of the event expressed by the verb. It was also argued for the existence of an additional feature set for pronouns. This set, called the sigma-set, contains syntactically encoded pragmatico-semantic information, and permits the so-called semantic agreement. 
Let us consider the sentences in (5) and (6), here repeated as (16) and (17):

(16) $\mathrm{Si}$ è andati fuori a cena

si is-3rd sg gone-past part pl masc out to dinner

'We went out for dinner'

(17) Si arriva

$\begin{array}{llll} & \text { sempre tardi se si prende } & \text { il treno } \\ \text { si arrives-3rd sg } & \text { always late if si takes-3rd sg } & \text { the } & \text { train }\end{array}$

'One always arrives late if one takes the train'

As stated in 4, I assume that when the event is unbounded, an [unbounded] feature is present on the aspectual head Asp. The sentence structure I assume, following Kempchinsky (2000) and Sigurősson (2002) is the one in (18), where EP is an inner aspectual (telicity) projection, AspP is the projection where sentential aspect is hosted, and Speech ActP encodes the pragmatic/deictic information which refers to the particular speech event:

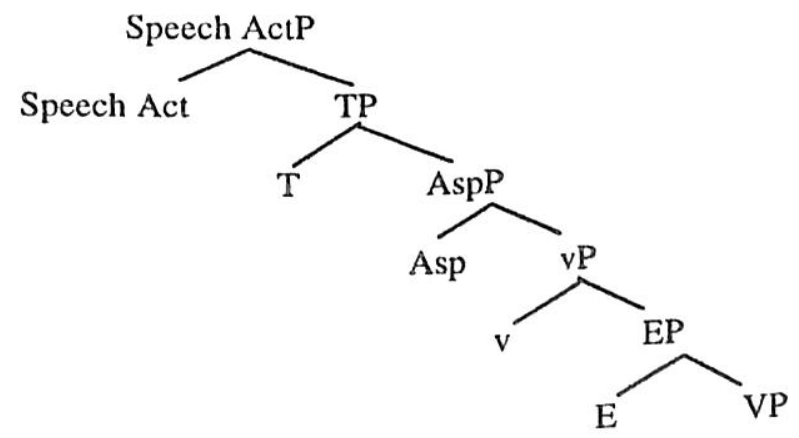

If we consider the sentence in (17), we can thus expect its derivation to run as follows: Impersonal si is merged with the VP, in the $\mathrm{EP}^{4}$. Impersonal si has the feature bundle listed in 3.4. In particular, it needs to have its sigma-person feature valued. When the Asp head is merged, it will carry the [underspecified] feature. The

4 I assume that impersonal si is merged in an inner aspectual projection, EP. The exact merging site of $s i$ is not relevant here, and hence I will not discuss it. 
sigma-feature bundle on si Matches the features on the Asp head. Concord is established and the si's sigma-person feature is valued as [unbounded]. This results in the generic reading for si. A tree-diagram of the derivation is offered in (19):

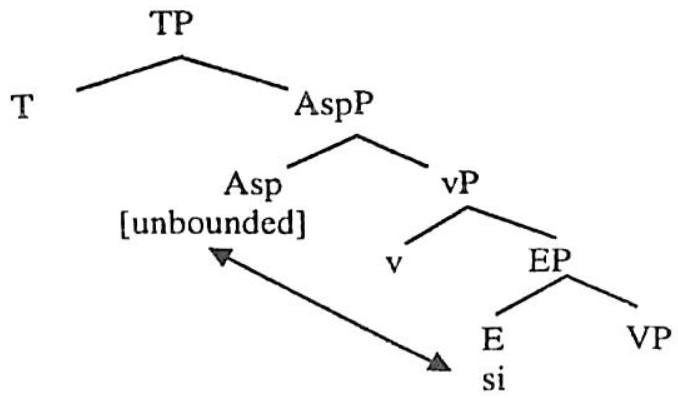

When the event is bounded, no [unbounded] feature is present on the Asp head. The sigma-person feature on $s i$ is thus valued by Concord with the Speech Act, which holds the closest valued sigmaperson feature, Speaker-Addressee:

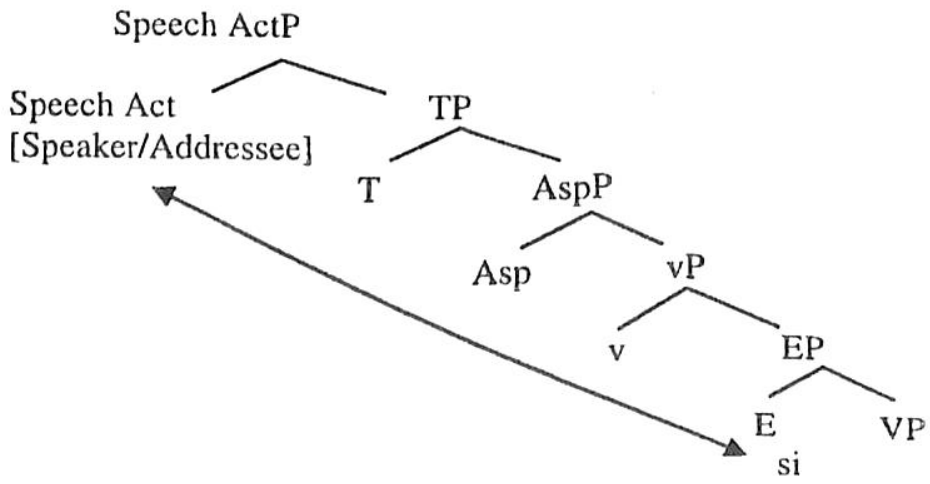

After Concord, si holds a plural sigma-number feature, a human sigma-animacy feature and a Speaker-Addressee sigma-person feature. Hence, the inclusive reading arises as the speaker is included among the participants in the event, then si will be obviously interpreted as 'we'.

To summarize: the valuation of the semantic person feature on si takes place via feature valuation by the Speech Act, which 
determines si's reference set. This happens when the event is bounded, and therefore when the [unbounded] feature is absent from the Asp head. The Speech Act encodes deictic information, i.e. attributes the values Speaker/Addressee to the pronoun according to the actual participants in the speech event.

\subsection{Portuguese $a$ gente}

Another example of sigma-feature valuation which results in syntactic agreement is the case of European Portuguese a gente.

As we saw in (12), here repeated as (21), European Portuguese a gente triggers a masculine plural agreement ending on the adjective in predicative constructions despite its feminine singular morphosyntactic specification:

(21) A gente está

cansados

a gente is $-3^{\text {rd }} \mathrm{sg}$

'People are tired'

tired-masc pl

For the analysis of (21), I will follow the proposal by Costa and Pereira (2003) according to which (21) involves a small clause. For the analysis of a gente, Costa and Pereira distinguish between syntactic and semantic agreement. Starting from their proposal, I wish to argue that what they call semantic agreement is in fact Concord, which targets the sigma-set. Concord obtains between the adjective and $s i$, while Agree holds between the copula and $s i$. The derivation of (21) is shown in (22). The sigma-features are indicated in CAPITALS, while the phi-features are indicated in bold:

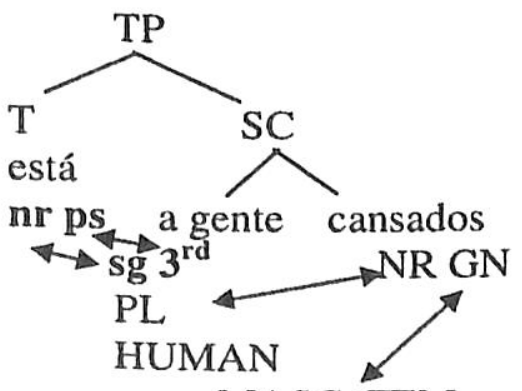

MASC+FEM 
In (22), Concord takes place within the small clause. The adjective cansados has unvalued number and gender sigma-features, which Match with the valued number and gender sigma-features on $a$ gente. The adjective is valued as masc + fem, resulting in a morphological masculine gender, which is the gender assigned to mixed groups in European Portuguese. It is also valued as plural.

Agreement on the copula targets instead phi-features. The phiperson feature on $\mathrm{T}$ is valued as $3^{\text {rd }}$, as a gente is $3^{\text {rd }}$ person. The phinumber person is instead singular.

The division of labour between phi-features and sigma-features provides a straightforward explanation for the facts at issue.

\section{Conclusions}

An agreement mechanism only based on phi-features is deficient in many ways. In this paper, I have shown that some agreement phenomena may not be accounted for by means of syntactic agreement which targets phi-features. After presenting some problematic data, I have proposed the existence of an additional feature set for pronouns, which I call the sigma-set. Sigma-features syntactically encode pragmatic/deictic information related to the actual participants in the speech event. I also propose that agreement between sigma-features takes place though Concord, which is the same operation as Agree but targets the sigma-set. With the adoption of this additional feature set, complex agreement phenomena, such as European Portuguese agreement with a gente and Italian agreement in impersonal si constructions follow without further ado.

\section{Acknowledgments}

I wish to thank Cláudia Roberta Tavares Silva for inviting me to write this short note. I also wish to thank Luigi Rizzi, Adriana Belletti, Ian Roberts, Andrew Nevins and Artemis Alexiadou for their precious suggestions. All mistakes are of course mine. 


\section{References}

ANAGNOSTOPOULOU, E. The syntax of ditransitives. Evidence from clitics. Berlin: Mouton de Gruyter, 2002.

BELLETTI, A. 'Morphological' passive and pro-drop: The impersonal construction in Italian. Journal of Linguistic Research 2, p. 1-34, 1982.

BIANCHI, V. On the syntax of personal arguments. Ms. University of Siena. 2003.

CHIERCHIA, G. The variability of impersonal subjects. In: BACH, E et al. (Eds.). Quantification in Natural Languages. Kluwer : Dordrecht, 1995, p. 107-143.

CHOMSKY, N. Derivation by Phase. MIT Occasional Papers in Linguistics 18. Cambridge: MIT Press., 1999.

CINQUE, G. On si constructions and the theory of arb. Linguistic Inquiry, n. 19, p. 521-582, 1988.

CINQUE, G. Italian syntax and Universal Grammar. Cambridge : Cambridge University Press, 1995.

COSTA, J.; PEREIRA, S. Phases and autonomous features: a case of mixed agreement in European Portuguese. Paper presented at the EPP/Phase Workshop at MIT, 2003.

D'ALESSANDRO, R. Impersonal si constructions. Agreement and interpretation. Doctoral diss. University of Stuttgart. 2004.

DOBROVIE-SORIN, C.. Impersonal se constructions in Romance and DOBROVIE-SORIN, C.. Impersonal se constructions in Rom 29 , 399-437,
the Passivization of Unergatives. Linguistic Inquiry, n. 29, p. 39.
1998.

GIORGI, A.; PIANESI, F. On the Speaker's and the Subject's Temporal Representation: The Case of the Italian Imperfect. In: GUERON, J; LECARME, J. The Syntax of Time. Cambridge: MIT Press, 2004.

HARLEY, H.; RITTER, E. Person and number in pronouns: a feature-geometric analysis. Ms. University of Arizona and University of Calgary. 2002. 
IATRIDOU, S.; ANAGNOSTOPOULOU, E.; PANCHEVA, R. Observations about the form and meaning of the Perfect, In: ALEXIADOU, A.; RATHERT, M.; VON STECHOW, A. (Eds.). Perfect Explorations. Berlin: Mouton de Gruyter, 2003.

KEMPCHINSKY, P. Aspect Projections and Predicate Type. In: Hispanic Linguistics at the Turn of the Millenium. Somerville: Cascadilla, 2000.

KRATZER, A. Impersonal pronouns and passive meaning. Ms. University of Massachusetts at Amherst. 1995.

KRATZER, A. German impersonal pronouns and logophoricity. Paper presented at the Generic pronouns and logophoricity Conference, São Paulo, 2000.

ORMAZABAL, J.; ROMERO, J. Agreement Restrictions. Ms. University of the Basque Country \& University of Alcalá. 2002.

SIGURĐSSON, H. Non-nominative subjects in Icelandic. Ms. University of Lund. 2002.

SIGUKĐSSON, H. Agree and Agreement: Evidence from Germanic. In: ABRAHAM, W. (Ed.). Argument Structure. Berlin: Akademieverlag, 2004:a.

SIGURĐSSON, H. Icelandic non-nominative subjects. In: BHASKARARAO, P; SUBBARAO, K. (Eds.). Non-nominative subjects. Amsterdam: John Benjamins, 2004:b.

SPEAS, M.. Evidentiality, logophoricity, and the syntactic representation of pragmatic features. Lingua, n. 114:3, p.255-276, 2004.

WECHSLER, S.; ZLATIĆ, L. A theory of Agreeement and its Application to Serbo-Croatian. Language, n. 76, v. 4, p. 799-832, 2001. 